\title{
Resistência natural da madeira de seis espécies à Nasutitermes corniger Motsch. em condição de campo
}

\section{Natural resistance of six wood species to Nasutitermes corniger Motsch. in field condition}

\author{
Felipe Gomes Batista', Rafael Rodolfo de Melo $12^{*}$, Leandro Calegari³ ${ }^{3}$ Dayane Targino de Medeiros² \\ e Pedro Jorge Goes Lopes ${ }^{4}$
}

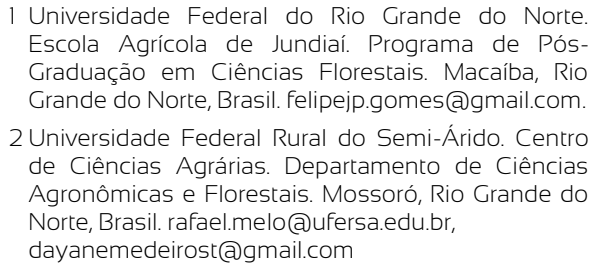
Escola Agrícola de Jundiaí. Programa de PósGraduação em Ciências Florestais. Macaíba, Rio Grande do Norte, Brasil. felipejp.gomes@gmail.com.

2 Universidade Federal Rural do Semi-Árido. Centro de Ciências Agrárias. Departamento de Ciências Agronômicas e Florestais. Mossoró, Rio Grande do Norte, Brasil. rafael.melo@ufersa.edu.br,

dayanemedeirost(a)gmail.com

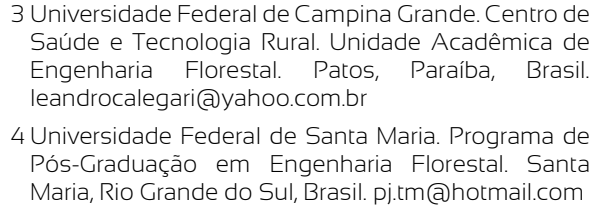

3 Universidade Federal de Campina Grande Centro de Saúde e Tecnologia Rural. Unidade Acadêmica de Engenharia Florestal. Patos, Paraíba, Brasil leandrocalegari@yahoo.com.br

4 Universidade Federal de Santa Maria. Programa de Pós-Graduação em Engenharia Florestal. Santa Maria, Rio Grande do Sul, Brasil. pj.tm@hotmail.com

\author{
* Autor de correspondencia. \\ rafael.melo@ufersa.edu.br
}

\section{RESUMO}

A durabilidade natural da madeira trata-se de excelente característica para destinar as peças de madeira em condições adequadas e eficientes de uso. Portanto, o estudo objetivou-se avaliar a resistência natural de seis espécies florestais madeireiras a cupins xilófagos em condição de campo. As madeiras estudadas das espécies tropicais foram andiroba (Carapa guianensis Aubl.), aroeira (Myracrodruon urundewva Allemão), cedro (Cedrella sp.), jatobá (Hymenaea courbaril L.), louro canela (Nectandra sp.) e maçaranduba (Manilkara elata (Allemão ex Miq.) Monach.). De cada espécie foram produzidas amostras com dimensões de 7,2 cm $\times 1,3 \mathrm{~cm} \times 0,9 \mathrm{~cm}$ (longitudinal $\times$ radial $\times$ tangencial). Essas permaneceram expostas por período de 40 dias sob a ação de cupins Nasutitermes corniger Motschulsky em ensaio de preferência alimentar, com determinação da densidade, percentual de perda de massa, índice de deterioração e o índice de susceptibilidade. A madeira de andiroba apresentou maior perda de massa e susceptibilidade ao ataque de $N$. corniger. Já as espécies cedro e o louro canela demonstraram valores intermediários entre as demais para os aspectos analisados. As madeiras de aroeira, jatobá e maçaranduba se destacaram nos valores de notas atribuídas ao desgaste, bem como, na baixa susceptibilidade ao ataque, tendo demonstrado maior durabilidade natural e resistência biológica ao ataque. Portanto, essas últimas madeiras são as mais indicadas para utilizações que visem promover o seu uso eficiente, a fim de minimizar os danos causados por exposição às térmitas (cupins) xilófagos e maximizar a vida útil e segurança do produto madeireiro.

PALABRAS CLAVE: durabilidade natural, espécies tropicais, térmitas subterrâneas.

\section{ABSTRACT}

The natural durability of the wood is an excellent characteristic for the use of wood parts under proper and efficient conditions of use. This work aimed to evaluate the natural resistance of six wood forest species to xylophagous termites in field conditions. The woods studied were Carapa guianensis Aubl, Myracrodruon urundewva Allemão, Cedrella sp., Hymenaea courbaril L., Nectandra sp. and Manilkara elata (Allemão ex Miq.) Monach. Test samples with dimensions of $7.2 \mathrm{~cm} \times 1.3 \mathrm{~cm} \times 0.9 \mathrm{~cm}$ (longitudinal $\times$ radial $\times$ tangential) were made from each wood species. They remained exposed for 40 days under the action of Nasutitermes corniger Motschulsky termites in a food preference test, Carapa guianensis wood presented greater mass loss and susceptibility to attack by N. corniger. On the other hand, the species Cedrella sp. and Nectandra sp. showed intermediate values among the others to the analyzed aspects. The woods of Carapa guianensis, Hymenaea courbaril and Manilkara elata stood out in the grade values attributed to the wear, as well as the low susceptibility. Therefore, these latter woods are best suited for use in order to promote their efficient use, minimize damage caused by exposure to xylophagous termites and maximize the useful life and safety of the timber product.

KEYWORDS: natural durability, tropical species, subterraneous térmites. 


\section{INTRODUÇÃO}

A madeira é o polímero natural de maior abundância no planeta, portanto, sendo utilizada pelo ser humano desde o início da civilização, como um dos principais materiais para cobrir necessidades construtivas, de abrigo ou moradia, locomoção e transporte, em utensílios cotidianos, bem como para diversas apreciações estéticas e artísticas (Makarona et al., 2017).

No ano de 2018, o Brasil produziu cerca de $11616 \mathrm{~m}^{3}$ de madeira em toras por meio do extrativismo vegetal, para emprego em diversos fins, assim foi gerada uma produção com receita na taxa de BRL 1,8 bilhão (Instituto Brasileiro de Geografia e Estatística [IBGE], 2019). Com base nisso, é necessário para o mercado madeireiro conhecer a qualidade do produto ofertado, visando o emprego eficiente da madeira em destino adequado, seja para construção civil, estruturas permanentes, indústria de móveis e afins.

A madeira de certas espécies florestais são importantes produtos econômicos nacional, devido a sua vasta utilização, como a Manilkara elata e Hymenaea courbaril em vigas estruturais e telhados, Cedrella sp. em peças de acabamento e móveis (Gonzaga, 2006), Myracrodruon urundewva em obras externas e na construção civil, Carapa guianensis e Nectandra sp. para mobiliário e construção civil leve (Instituto de Pesquisas Tecnológicas [IPT], 2019).

Para diversas aplicações da madeira, a durabilidade natural é uma característica primordial, pois em espécies florestais que possuem alta resistência à biodeterioração, é desnecessário a utilização de produtos químicos com a finalidade de aumentar seu tempo em serviço, diminuindo os impactos ambientais e os gastos desnecessários com a substituição de peças, garantindo, assim, por maior período de tempo a integridade nas construções civis e na segurança das pessoas que dela fazem uso (Stallbaun et al., 2017).

Porém, apesar do uso intensivo, a madeira é vulnerável à ação de organismos xilófagos, conforme as condições de temperatura, umidade, aeração e insolação que é exposta, capaz de proporcionar menor ou maior deterioração ao material madeireiro (Ribeiro et al., 2014).
Dentre os organismos xilófagos, os cupins são os mais conhecidos por serem frequentemente visualizados e combatidos, pois são considerados pragas por humanos e apresentarem ampla distribuição nos meios urbano e rural. São insetos da subordem Isoptera (Ordem Blattodea), que contêm cerca de 3166 espécies catalogadas no mundo, com 661 delas ocorrendo na Região Neotropical (Krishna, Grimaldi, Krishna e Engel, 2013; Constantino, 2017). São conhecidos por sua importância econômica como pragas da madeira e de materiais lignocelulósicos afins, no qual têm atraído à atenção de muitos pesquisadores por serem insetos sociais (eussociais) (Constantino, 2015, 2017).

Os cupins do gênero Nasutitermes (Termitidae: Nasutitermitinae) constroem normalmente suas colônias em locais acima da superfície do solo, em troncos, ou galhos ou ramos das árvores. A construção dos ninhos geralmente ocorre durante a estação chuvosa, sendo e estruturados a partir de madeira digerida e certos componentes, como areia cimentada com fluidos fecais e salivares (Cruz et al., 2014). Segundo He et al. (2013); Krishna et al. (2013), os cupins do gênero Nasutitermes são os mais diversificados contendo 254 espécies catalogadas, 114 delas na Região Neotropical, alimentam-se de madeira seca, úmida ou parcialmente decomposta. Dentre as espécies desse gênero, Paes, Guerra, Silva, Oliveira e São Teago (2016) relataram que os cupins da espécie Nasutitermes corniger é habitualmente encontrada em várias regiões do Brasil, com ataque às estruturas de madeira empregadas nos meios urbano e rural.

\section{OBJETIVOS}

Diante da necessidade de investigações que avaliem a durabilidade das espécies madeireiras tropicais de considerável importância comercial, a fim de aperfeiçoar o uso e evitar gastos desnecessários com a reposição prematura de peças deterioradas. O trabalho teve como objetivo avaliar a resistência natural de seis espécies florestais madeireiras a cupins $N$. corniger em condição de campo. 


\section{MATERIAIS E MÉTODOS}

\section{Espécies estudadas}

Para realização do estudo utilizaram-se madeiras de seis espécies florestais provenientes de diferentes estabelecimentos madeireiros localizados no município de Patos, Paraíba, Brasil, conforme tabela 1.

TABELA 1. Relação das espécies madeireiras estudadas.

\begin{tabular}{ll}
\hline $\begin{array}{l}\text { Nome } \\
\text { Comum }\end{array}$ & Nome Científico \\
\hline Andiroba & Carapa guianensis Aubl. \\
Aroeira & Myracrodruon urundeuva Allemão \\
Cedro & Cedrella sp. \\
Jatobá & Hymenaea courbaril L. \\
Louro canela & Nectandra sp. \\
Maçaranduba & Manilkara elata (Allemão ex Miq.) Monach. \\
\hline
\end{tabular}

O critério de seleção foi decorrente da comercialização no mercado da construção civil para fins de estruturas permanentes, como vigas, caibros e tábuas, visto que estes usos expõem à madeira a alto risco de ataque por agentes xilófagos. Como referência de comparação utilizou-se a madeira de Pinus sp. no ensaio de preferência alimentar, por causa de sua susceptibilidade ao ataque de cupins.

\section{Produção dos corpos de prova}

Das madeiras obtidas, foram produzidos corpos de prova com dimensões de 7,2 cm $\times 1,3 \mathrm{~cm} \times 0,9 \mathrm{~cm}$ (longitudinal $\times$ radial $\times$ tangencial), sendo selecionados 20 corpos de prova para cada espécie madeira, compostos apenas de cerne interno e isentos de quaisquer defeitos, como rachaduras, presença de nós e esmoado.

Os corpos de prova foram secos em estufa a $103{ }^{\circ} \mathrm{C} \pm$ $2{ }^{\circ} \mathrm{C}$, até atingirem massa constante. A massa seca de cada corpo de prova foi obtida em balança $(0,01 \mathrm{~g}$ de precisão), de acordo com a American Society for Testing and Materials - ASTM D-3345 (2017), tais valores utilizados para determinação da densidade e perda de massa dos corpos de prova submetidos ao ataque de $N$. corniger.

\section{Resistência natural da madeira a cupins xilófagos}

O ensaio de preferência alimentar foi montado diretamente em nove colônias arborícolas de N. corniger. Desta forma, os corpos de prova foram distribuídos aleatoriamente entre dois e três grupos nas colônias de cupins, sendo cada grupo composto pelas seis espécies de interesse e uma espécie de referência (Pinus sp.), conforme demonstrado na figura 1.

Os corpos de prova permaneceram expostos por período de 40 dias sob ação dos cupins. Após a remoção, os corpos de prova foram limpos com uma escova para retirada do material que compõe a colônia de cupins (argila, areia, saliva e excrementos dos próprios cupins) e, submetidos ao condicionamento nas mesmas condições iniciais (secos e pesados secagem e mensuração da massa). Com base nesses dados, determinou-se a perda percentual de massa das amostras após o ataque pelo cupim xilófago.

Por sua vez, as avaliações visuais foram procedidas por três pessoas distintas, ao empregar um sistema subjetivo de notas (Tabela 2), no qual relaciona o estado de sanidade da madeira como índice de deterioração, sugerido por Lepage (1970).

TABELA 2. Avaliação qualitativa do desgaste provocado por cupins nos corpos de prova de madeira.

\begin{tabular}{lcc}
\hline Descrição & Notas & $\begin{array}{c}\text { Índice de } \\
\text { Deterioração }\end{array}$ \\
\hline $\begin{array}{l}\text { Sadio, permitindo } \\
\text { escarificação superficial }\end{array}$ & 10 & 100 \\
$\begin{array}{l}\text { Ataque leve ou superficial } \\
\begin{array}{l}\text { Ataque moderado, havendo } \\
\text { penetração }\end{array}\end{array}$ & 9 & 90 \\
$\begin{array}{l}\text { Ataque intenso } \\
\text { Ruptura dos corpos de prova }\end{array}$ & 0 & 70 \\
\hline
\end{tabular}

Fonte: Lepage (1970).

Além disso, os corpos de prova foram avaliados quanto ao índice de susceptibilidade ao ataque (ISA) proposto por Curling e Murphy (2002), no qual relaciona a perda de massa de uma determinada madeira de interesse com a de uma madeira de referência (Pinus sp.) (Equação 1). 

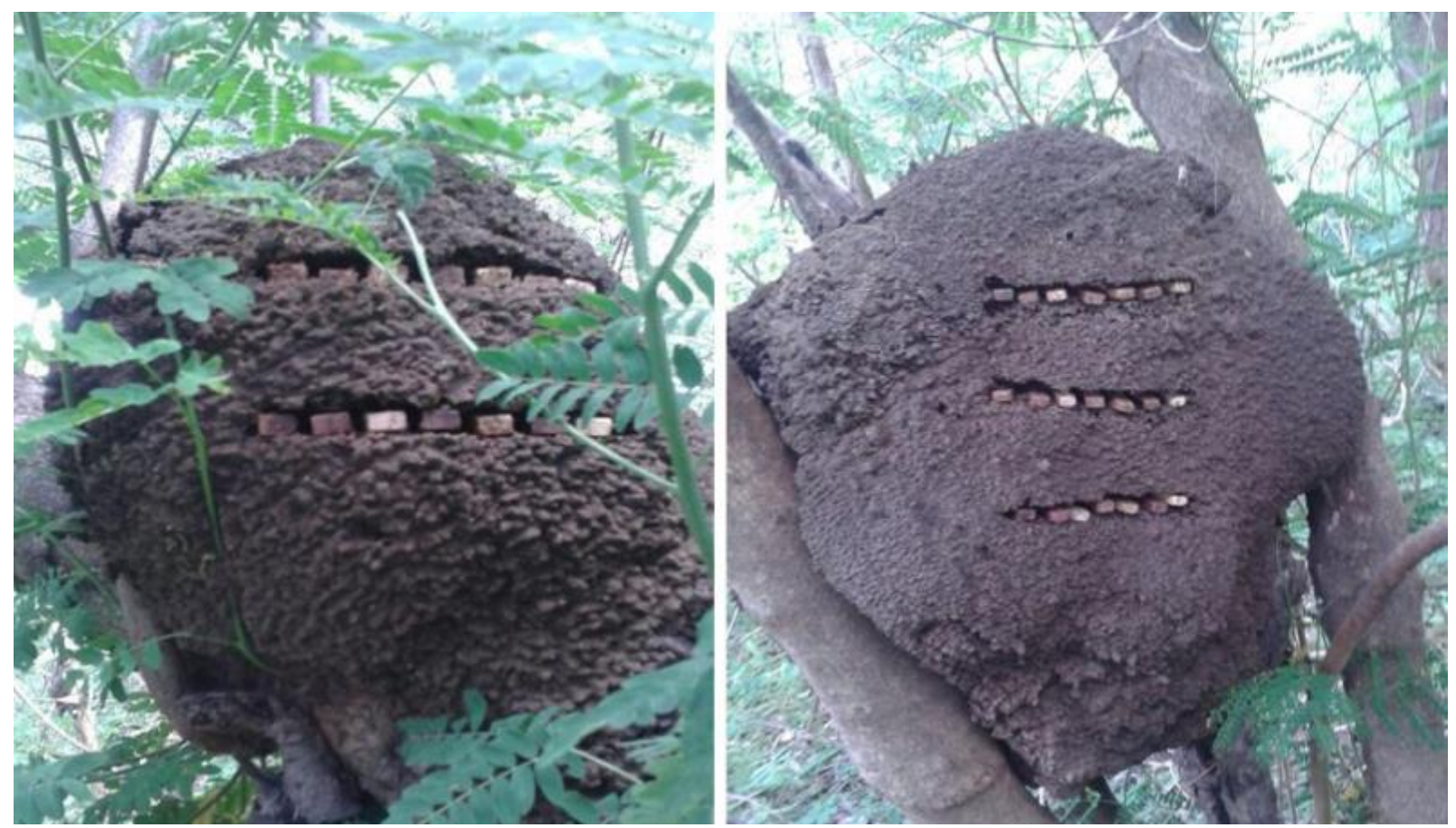

FIGURA 1. Implantação e distribuição dos corpos de provas das espécies madeireiras em colônias arborícolas de N. corniger, no município de Patos, Paraíba, Brasil.

$$
\mathrm{ISA}=\frac{\mathrm{PMa}}{\mathrm{PMr}} * 100
$$

Em que:

ISA = Índice de susceptibilidade ao ataque (\%)

$\mathrm{PMa}=$ Perda de massa da madeira de interesse $(\%)$

$\mathrm{PMr}=$ Perda de massa da madeira de referência $(\%)$

\section{Análise estatística dos dados}

No estudo empregou-se o delineamento em blocos casualizados. Os dados para perda de massa, índice de deterioração (notas) e susceptibilidade ao ataque foram submetidos à análise de variância (ANOVA) e teste F de Fisher-Snedecor, constatadas diferenças significativas, aplicou-se a comparação de médias pelo teste de Tukey.

Com as informações dos valores médios da densidade para fonte de variação entre eles aplicaram-se modelos de regressão, com transformação dos dados (logaritmo neperiano) e anterior verificação das pressuposições estatísticas (normalidade, homocedasticidade e independência dos resíduos). Em todos os casos considerou-se ao nível de 5\% de significância.

\section{Resultados}

As seis espécies madeireiras foram consumidas pelos cupins $N$. corniger, os quais ocasionaram diferentes graus de lesões de amostras de madeira (Tabela 3). Vale ressaltar que no ensaio de preferência alimentar empregado no estudo, os cupins possuem outras fontes alimentares em seu hábitat, portanto atacam mais intensamente os alimentos disponíveis no ambiente de sua preferência, seja entre as madeiras estudadas ou não.

Nota-se com base no ISA que os cupins atacaram preferencialmente as espécies madeireiras menos densas, constatou-se, assim, que as madeiras com alta densidade apresentaram maior resistência sob o ataque desses agentes xilófagos.

Verificou-se que ocorreu diminuição na perda de massa em madeiras com maior a densidade sob ataque dos cupins N. corniger (Fig. 2), com destaque nesta lógica para as espécies aroeira, maçaranduba e jatobá. Além das propriedades físicas da madeira, esse comportamento também ocorre em função da composição química do material, considerando os teores de lignina, percentual de 
cinzas (compostos inorgânicos) e os tipos de extrativos que influenciam na resistência das madeiras ao ataque de cupins xilófagos.

Os menores níveis de desgaste foram apresentados pelas madeiras com elevada densidade, aroeira e maçaranduba, enquanto a andiroba forneceu registros que denotam maior desgaste, sendo, inclusive, mais desgastada que a própria madeira de pinus, pela ação de N. corniger (Fig. 3).
A correlação simples de Pearson entre o desgaste e a perda de massa das espécies madeireiras foi de 83,1\%. Destaca-se que a perda de massa da madeira decresceu com o aumento das notas de desgaste (Fig. 4), a concentração das notas localiza-se principalmente entre 8 e 10, engloba assim, a maioria das madeiras analisadas, a exceção da andiroba que obteve a maior perda de massa e menor nota de resistência ao índice de deterioração (desgaste).

TABELA 3. Valores médios da densidade básica, perda de massa, índice de deterioração (notas) e de susceptibilidade ao ataque das madeiras submetidas ao cupim N. corniger.

\begin{tabular}{lcccc}
\hline Madeiras & Densidade $\left(\mathrm{g} \mathrm{cm}^{-3}\right)$ & $P M(\%)$ & Notas & $I S A(\%)$ \\
\hline Andiroba & $0,552 \pm 0,026$ & $2,09 \mathrm{a} \pm 2,16$ & $7,68 \mathrm{c} \pm 1,97$ & $124,98 \mathrm{a} \pm 25,35$ \\
Aroeira & $1,129 \pm 0,036$ & $0,08 \mathrm{c} \pm 0,13$ & $10,00 \mathrm{a} \pm 0,00$ & $3,57 \mathrm{~d} \pm 1,88$ \\
Cedro & $0,444 \pm 0,015$ & $1,63 \mathrm{ab} \pm 1,80$ & $8,93 \mathrm{~b} \pm 0,95$ & $88,84 \mathrm{~b} \pm 19,12$ \\
Jatobá & $0,847 \pm 0,069$ & $0,20 \mathrm{c} \pm 0,27$ & $9,79 \mathrm{ab} \pm 0,49$ & $10,20 \mathrm{~d} \pm 4,66$ \\
Louro canela & $0,480 \pm 0,026$ & $0,56 \mathrm{bc} \pm 0,48$ & $9,14 \mathrm{ab} \pm 0,71$ & $33,68 \mathrm{c} \pm 9,31$ \\
Maçaranduba & $0,864 \pm 0,055$ & $0,10 \mathrm{c} \pm 0,15$ & $9,90 \mathrm{a} \pm 0,17$ & $6,11 \mathrm{~d} \pm 2,35$ \\
Pinus (controle) & $0,410 \pm 0,067$ & $1,72 \pm 1,77$ & $7,87 \pm 1,20$ & - \\
\hline
\end{tabular}

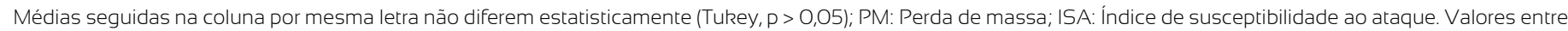
parênteses correspondem ao erro padrão.

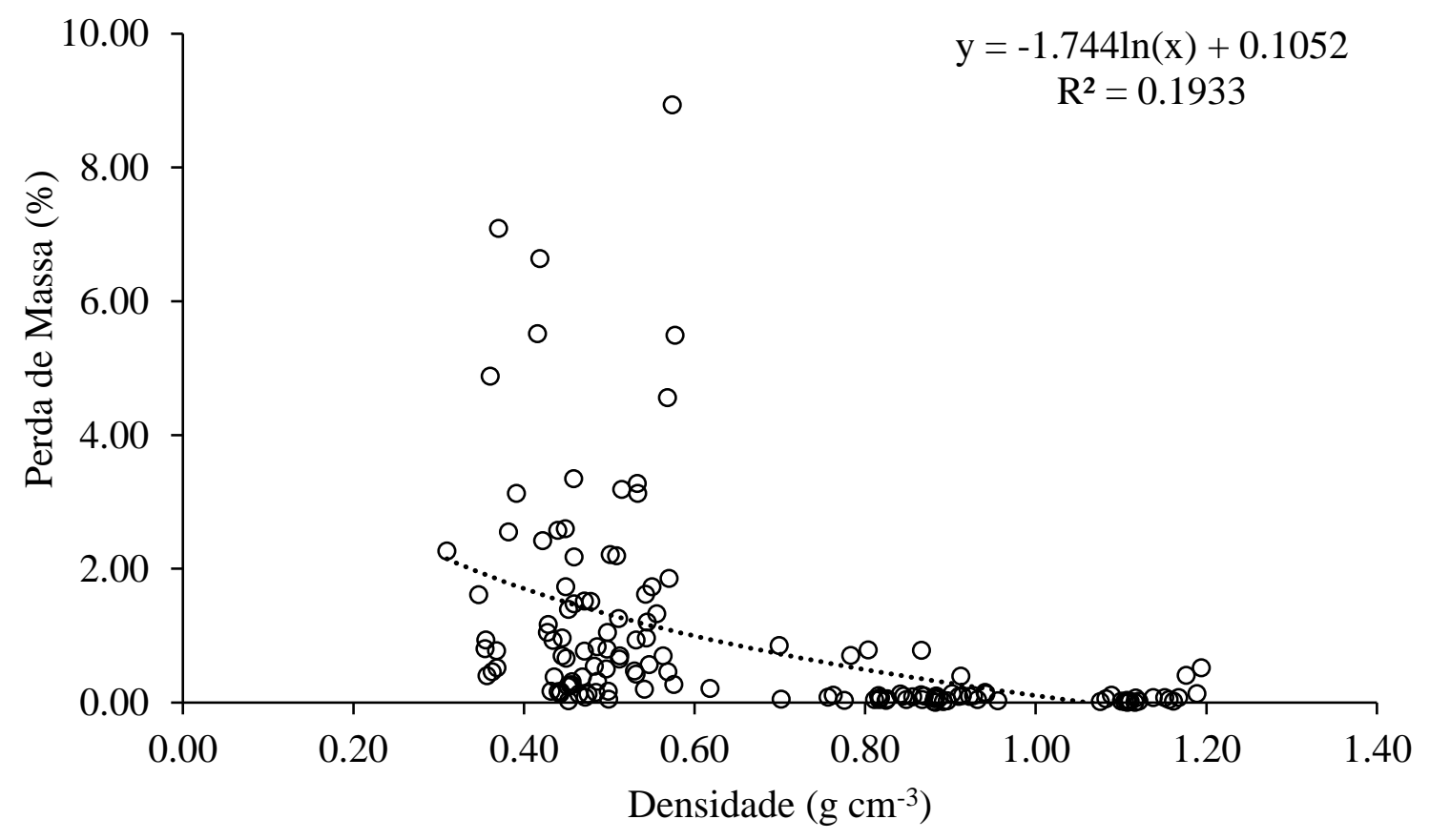

FIGURA 2. Variação da perda de massa em função da densidade das espécies florestais madeireiras. 


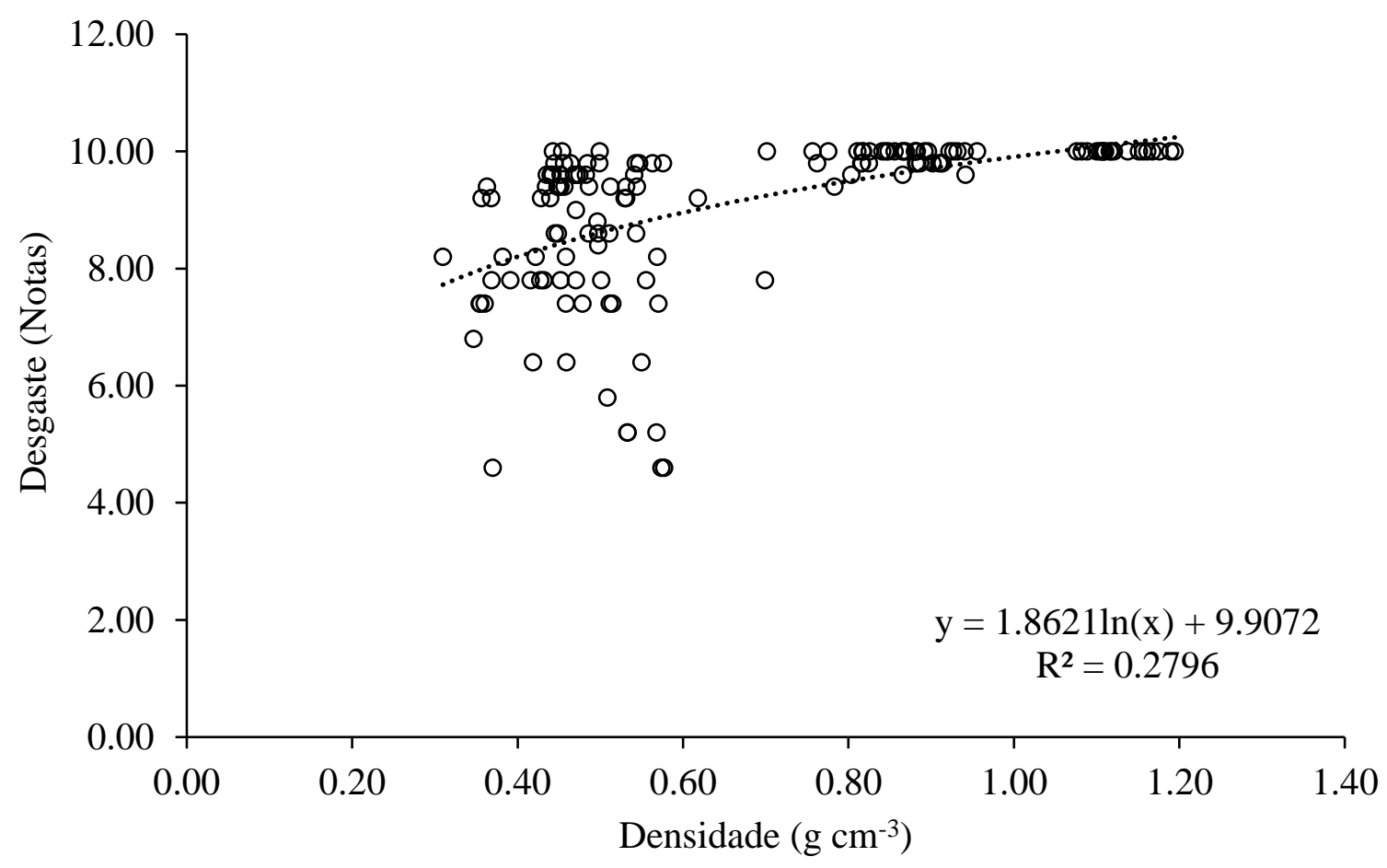

FIGURA 3. Variação do grau de deterioração (desgaste/notas) em função da densidade das espécies florestais.

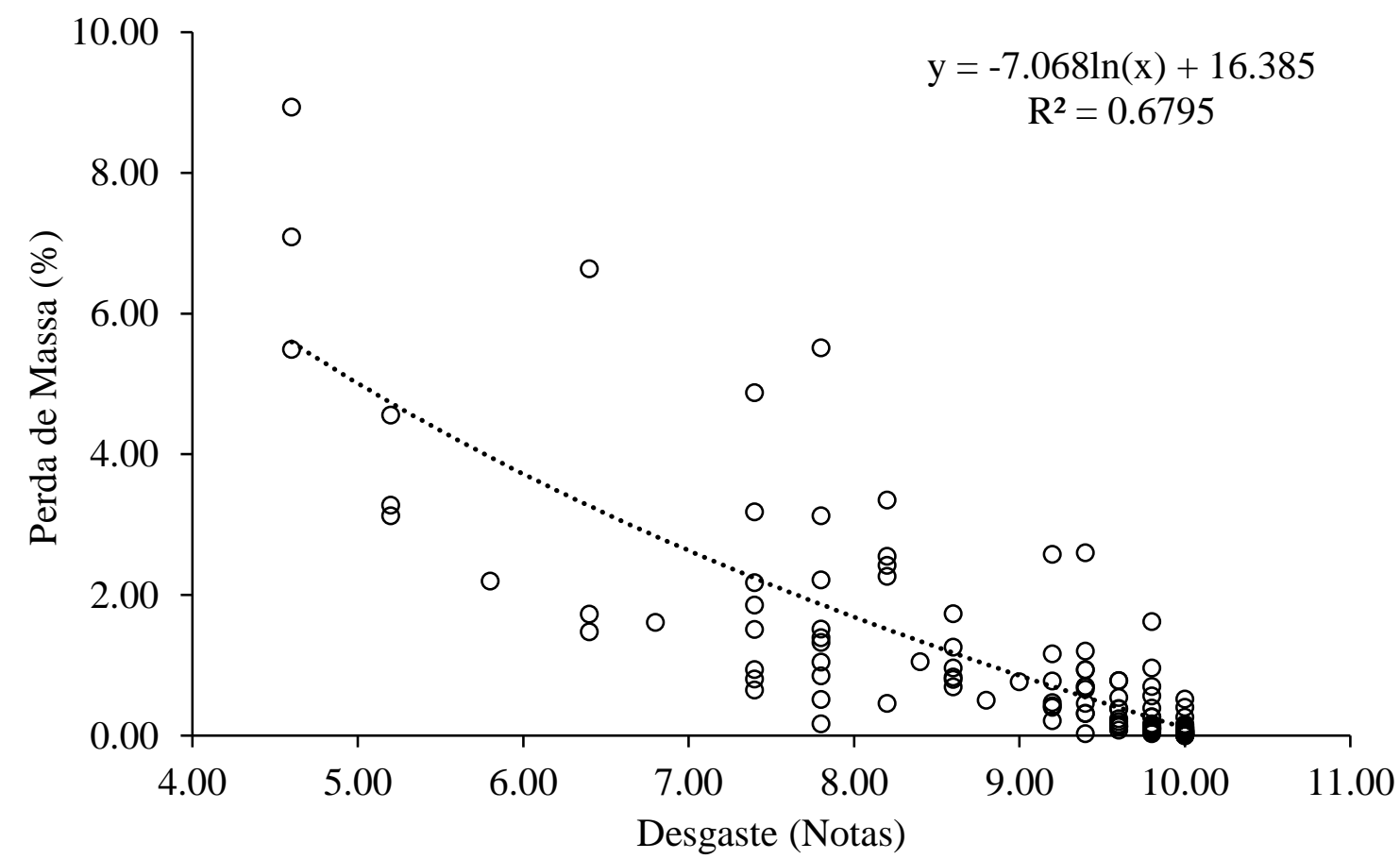

FIGURA 4. Variação da perda de massa em função do grau de deterioração (desgaste/notas) das espécies florestais madeireiras. 
Quanto ao índice de susceptibilidade ao ataque em relação à densidade das madeiras analisadas (correlação entre as variáveis de 68,6\%), observa-se que a susceptibilidade das madeiras aos cupins $N$. corniger diminui em função do aumento da densidade (Fig. 5). Pois, a quantidade de material lenhoso influencia diretamente na dureza da madeira, isso confere-se resistência física a esse substrato, pois os cupins supostamente têm dificuldade de danificar a madeira pela ação das mandíbulas. As madeiras mais resistentes foram à aroeira, jatobá e maçaranduba, com variação entre $3,57 \%$ e 10,20\%. Porém, a andiroba, cedro e louro canela apresentaram alta susceptibilidade ao ataque de cupins com valor máximo de 124,98\%.

De forma generalista, o estudo apresenta resultados consistentes do comportamento natural das madeiras, de interessante valor econômico e uso, frente a ação de cupim xilófago. Porém, o tempo de exposição curto ao ataque pelos térmitas influenciou de forma significativa a representatividade menos exacerbada dos resultados, sendo necessário tempo mais prolongado de exposição, em vista de compreender melhor o comportamento da biodeterioração das madeiras menos densas em relação às de maior valor dessa característica.

\section{DISCUSSÃO}

Dentre os valores médios das madeiras analisadas, a andiroba foi à espécie mais atacada pelos cupins $N$. corniger, tendo apresentado maior perda de massa $(2,09 \%)$, menores notas atribuídas ao índice de deterioração $(7,86)$ e o maior índice de susceptibilidade ao ataque com 124,98\%. Conforme Curling e Murphy (2002), madeira com índice de susceptibilidade acima de 100\% significa que é menos resistente em relação à espécie referência (Pinus sp.) e, índice abaixo de 100\%, indica maior grau de resistência da espécie em estudo.

As madeiras de alta densidade, como aroeira, maçaranduba e jatobá tendem a diminuir a capacidade de alimentação por parte dos cupins, fato que dificulta assim seu consumo (Stallbaun et al., 2017), pois é necessária menor quantidade de volume para satisfazer a necessidade de alimento por parte dos cupins xilófagos. Além dessas madeiras possivelmente apresentarem maior teor de compostos extrativos no lenho, conforme Bowyer, Shmulsky e Haygreen (2003).

Porém, vale destacar que há madeiras de baixa densidade e elevada resistência ao ataque de térmitas, ou seja, pouca susceptibilidade à deterioração. Tal fato devido à presença e, principalmente, qualidade de certos compostos extrativos (classificação química), esse último aspecto deve ser considerado em destaque conjuntamente aos demais parâmetros já abordados.

A densidade da madeira é uma propriedade essencial para avaliação do potencial de utilização do respectivo material biológico. Madeiras que apresentam densidade superior a $0,80 \mathrm{~g} \mathrm{~cm}^{-3}$ (como a aroeira, jatobá e maçaranduba) tendem a possuir maior resistência ao desgaste natural, seja o mesmo ocasionado por meio de fatores abióticos (como a luz solar, umidade e compostos químicos do solo) e os bióticos (organismos xilófagos ou deterioradores). Essa característica está associada intrinsecamente a outros fatores, os quais influenciam na sua resistência natural como a composição química da biomassa lenhosa (tipos e quantidade de extrativos, e lignina e cinzas) e a relação cerne:alburno.

Como mencionado além das propriedades físicas da madeira, esse comportamento também ocorre em função da composição química do material. Os compostos extrativos (orgânicos), cinzas (inorgânicos) e a lignina presentes na madeira podem atuar de forma a promover certa proteção e defesa contra o ataque de biodeterioradores. As três espécies madeireiras citadas acima apresentam taxas elevadas desses componentes, com base na literatura científica. Segundo Silva, Oliveira, Calegari, Pimenta e Dantas (2017), o teor de extrativos da espécie aroeira (Myracrodruon urundewva) corresponde a 12,7\%; 1,08\% e 27,1\%, respectivamente. Já Ferreira (2017) determinou as características químicas de resíduos da madeira de maçaranduba (Manilkara elata) e determinou $14,3 \%$ de extrativos totais, $0,72 \%$ de cinzas e $32,3 \%$ de lignina total. O lenho do jatobá (Hymenaea courbari) contém $12,7 \%$ de extrativos totais em sua constituição; $0,36 \%$ de minerais e $31,8 \%$ de lignina, conforme citado por Castro et al. (2015). 


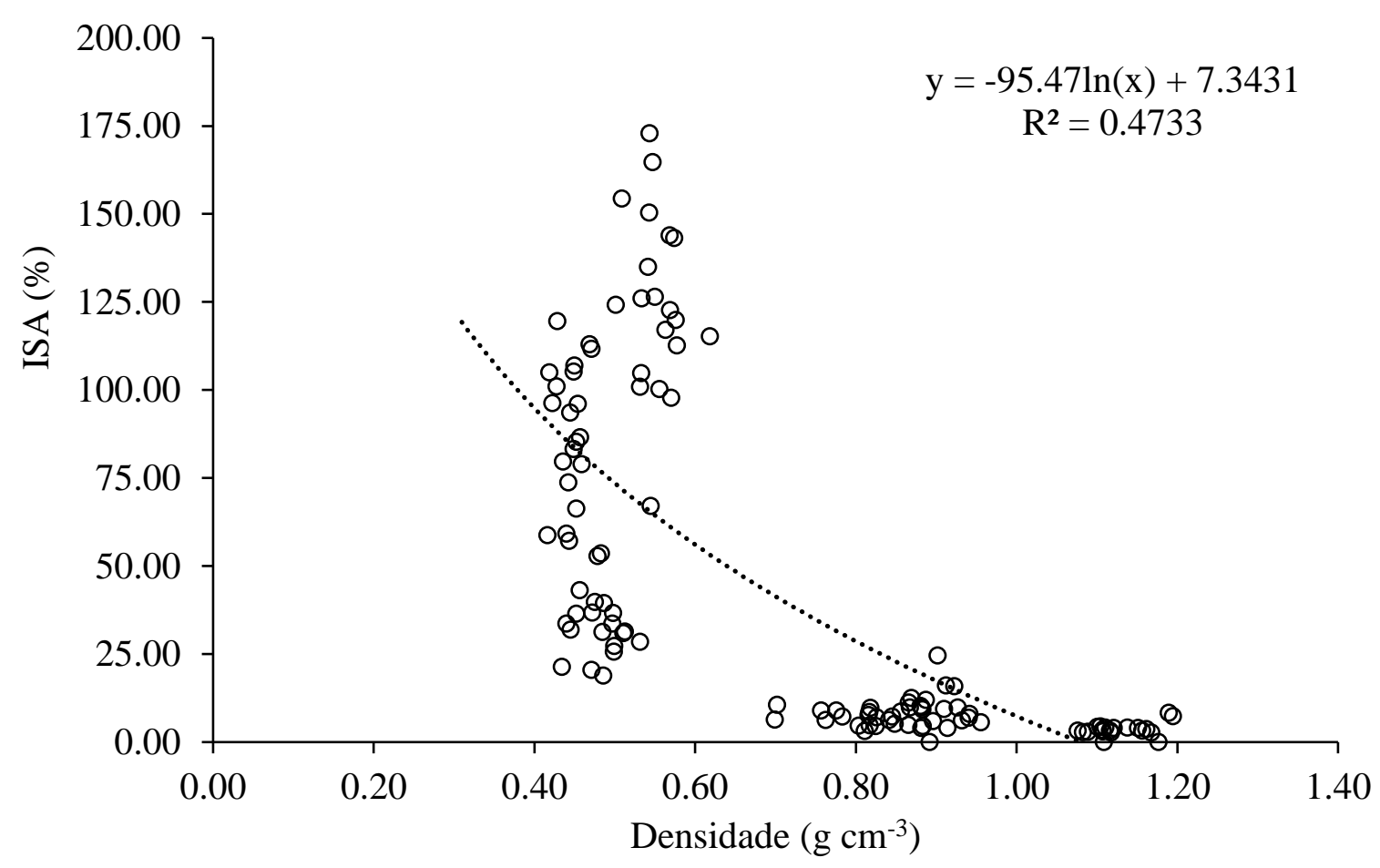

FIGURA 5. Variação do índice de susceptibilidade ao ataque (ISA) em função da densidade das espécies florestais madeireiras.

No entanto, autores como Paes, Medeiros Neto, Lima, Freitas e Diniz Paes et al. (2013) e Paes et al. (2016) afirmam que a relação da resistência biológica não deve-se basicamente ao aspecto quantitativo dos extrativos na constituição da madeira, e sim aos tipos e localização dos extrativos orgânicos na célula lenhosa e, ou, cinzas, pois propiciam dificuldades do material madeireiro ser escarificado e consumido pelos insetos.

As madeiras utilizadas eram compostas essencialmente de cerne, essa estrutura macroscópica perde a função fisiológica do vegetal ao passar do tempo, sendo depositado no seu interior diversas substâncias, principalmente, os compostos extrativos. Esses compostos podem ser tóxicos aos biodeterioradores da madeira, o qual promove maior resistência ao cerne sob o ataque de térmitas.

\section{CONCLUSÕES}

De forma geral, conclui-se que a madeira de andiroba, dentre as espécies estudadas, apresentou maior suscep- tibilidade ao ataque de cupins N. corniger. O cedro e louro canela exibiram valores intermediários de resistência dentre as espécies madeireiras estudadas para os aspectos analisados.

As madeiras de aroeira, jatobá e maçaranduba demonstram maior resistência biológica (durabilidade natural) à ação dos cupins xilófagos, sendo as mais indicadas para serem utilizadas em locais com incidência desses insetos.

\section{REFERÊNCIAS}

American Society for Testing and Materials [ASTM] (2017). ASTM D3345: Standard method for laboratory evaluation of wood and other cellulosic materials for resistance to termites. En Annual Book of ASTM Standards 4(10) (pp. 430-432).

Bowyer, J. L., Shmulsky, R., \& Haygreen, J. G. (2003). Forest products and wood Science: an introduction (4th ed.). Ames, United States of America: Iowa State Press.

Castro, J. P., Perígolo, D. M., Bianchi, M. L., Mori, F. A., Fonseca, A. S., Alves, I. C. N., \& Vasconcelos, F. J. Uso de espécies amazônicas 
para envelhecimento de bebidas destiladas: análises física e química da madeira. Cerne, 21(2), 319-327. doi: 10.1590/ 01047760201521021567

Constantino, R. (2015). Cupins do Cerrado (1 $1^{\mathrm{a}}$ ed.). Rio de Janeiro, Brasil: Technical Books.

Constantino, R. (2017). Termite database: statistics of family, number of genera and number of species. Recuperado de http://www.termitologia.net/ termite-database

Cruz, M. N. S., Junior, H. M. S. J., Rezende, C. M., Alves, R. J. V., Cancello, E. M. \& Rocha, M. M. (2014). Terpenos em cupins do gênero Nasutitermes (Isoptera, Termitidae, Nasutitermitinae). Quimica Nova, 37(1), 95-103. doi: 10.1590/S010040422014000100018

Curling S. F. \& Murphy, R. J. (2002). The use of the Decay Susceptibility Index (DSI) in the evaluation of biological durability tests of wood based board materials. Holz als Roh und Werkestoff, 60(3), 224226. doi: 10.1007/s00107-002-0284-2

Ferreira, G. (2017). Viabilidade técnica da produção de pellets de resíduos de madeira das espécies Dinizia excelsa Ducke e Manilkara elata (Allemão ex Miq.) Monach. para fins energéticos. Tesis de maestria, Universidade Federal do Espírito Santo, Jerônimo Monteiro, Brasil.

Gonzaga, A. L. (2006). Madeira: uso e conservaşão. (Caderno Técnico, 6). Brasília, Brasil: IPHAN/MONUMENTA.

He, S., Ivanova, N., Kirton, E., Allgaier, M., Bergin, C., Scheffrahn, R. H., Kyrpides, N. C., Warnecke, F., Tringe, S. G. \& Hugenholtz, P. (2013). Comparative metagenomic and metatranscriptomic analysis of hindgut paunch microbiota in wood- and dung-feeding higher térmites. Plos One, 8(4), e61126. doi: 10.1371/journal.pone.0061126

Instituto Brasileiro de Geografia e Estatística [IBGE]. (2018) Produção da extração vegetal e da silvicultura (PEVS) 2018. Recuperado de https://sidra.ibge.gov.br/tabela/289

Instituto de Pesquisas Tecnológicas [IPT]. (2019). Informações sobre madeiras. Recuperado de https://www.ipt.br/consultas_online

Lepage, E. S. (1970). Manual de preservação de madeiras. São Paulo, Brasil: IPT.

Krishna, K., Grimaldi D. A., Krishna, V., \& Engel, M. S. (2013). Treatise on the Isoptera of the world: 3 Neoisoptera excluding Termitidae. Bulletin of the American Museum Natural History, 3(1), 1-377.

Makarona, E., Koutzagioti, C., Salmas, C., Ntalos, G., Skoulikidou, M. C., \& Tsamis, C. (2017). Enhancing wood resistance to humidity with nanostructured $\mathrm{ZnO}$ coatings. Nano-Structures \& NanoObjects, 10(2), 57-68. doi: 10.1016/j.nanoso.2017.03.003
Paes, J. B., Medeiros Neto, P. N., Lima, C. R., Freitas, M. F., \& Diniz, C. E. F. (2013). Efeitos dos extrativos e cinzas na resistência natural de quatro madeiras a cupins xilófagos. Cerne, 19(3), 399-405. doi: 10.1590/S0104-77602013000300006

Paes, J. B., Guerra, S. C. S., Silva, L. F., Oliveira, J. G. L., \& São Teago, G. B. (2016). Efeito do teor de extrativos na resistência natural de cinco madeiras ao ataque de cupins xilófagos. Ciência Florestal, 26(4), 1259-1269. doi: 10.5902/1980509825137

Ribeiro, M. A., Stangerlin, D. M., Souza, A. P., Cardoso. G. V., Calegari, L., \& Gatto, G. A. (2014). Durabilidade natural da madeira de jequitibá em ensaios de deterioração em campo aberto e floresta durante as estações de seca e chuva. Comunicata Scientiae, 5(4), 402411. doi: $10.14295 /$ cs.v5i4.262

Silva, L. L. H., Oliveira, L., Calegari, L., Pimenta, M. C., \& Dantas, M. K. L. (2017). Características dendrométricas, físicas e químicas da Myracrodruon urundeuva e da Leucaena leucocephala. Floresta e Ambiente, 24(1), e20160022. doi: 10.1590/2179-8087.002216

Stallbaun, P. H., Barauna, E. E. P., Paes, J. B., Ribeiro, N. C., Monteiro, T. C., \& Arantes, M. D. C. (2017). Resistência natural da madeira de Sclerolobium paniculatum Vogel a cupins em condições de laboratório. Floresta e Ambiente, 24(1), e20160013. doi: 10.1590/ 2179-8087.001316

Recebido: 19 junho 2019

Aceito: 2 outubro 2019

Publicado: 23 abril 2020

\section{Este documento se debe citar como:}

Batista, F. G., Melo, R. R., Calegari, L., Medeiros, D. T., \& Lopes, P. J. G. (2020). Resistência natural da madeira de seis espécies à Nasutitermes corniger Motsch. em condição de campo. Madera y Bosques, 26(2), e2622017. doi: 10.21829/myb.2020.2622017

Madera y Bosques por Instituto de Ecología, A.C. se distribuye bajo una Licencia Creative Commons Atribución-NoComercialCompartirlgual 4.0 Internacional. 